Article

\title{
Screening of Diverse Ethiopian Durum Wheat Accessions for Aluminum Tolerance
}

\author{
Edossa Fikiru Wayima ${ }^{1}{ }^{(0)}$, Ayalew Ligaba-Osena ${ }^{2}$, Kifle Dagne ${ }^{3}$, Kassahun Tesfaye ${ }^{3}{ }^{(1)}$, \\ Eunice Magoma Machuka ${ }^{4}$, Samuel Kilonzo Mutiga ${ }^{4}$ (D) and Emmanuel Delhaize ${ }^{5, * \text { (D) }}$ \\ 1 Department of Plant Sciences, College of Agriculture and Natural Resources, Madda Walabu University, \\ Bale-Robe P.O. Box 247, Ethiopia \\ 2 Laboratory of Molecular Biology and Biotechnology, The University of North Carolina at Greensboro, \\ 321 McIver St., 308 Sullivan Science Building, Greensboro, NC 27412, USA \\ 3 Cellular and Molecular Biology Department, College of Natural Sciences, Addis Ababa University, \\ Addis Ababa P.O. Box 1176, Ethiopia \\ 4 Biosciences Eastern and Central Africa-International Livestock Research Institute (BecA-ILRI) Hub, Nairobi \\ P.O. Box 30709-00100, Kenya \\ 5 CSIRO Agriculture and Food, GPO Box 1700, Canberra 2601, Australia \\ * Correspondence: manny.delhaize@csiro.au
}

Received: 15 July 2019; Accepted: 7 August 2019; Published: 9 August 2019

Abstract: Acid soils and associated $\mathrm{Al}^{3+}$ toxicity are prevalent in Ethiopia where normally $\mathrm{Al}^{3+}$-sensitive durum wheat (Triticum turgidum ssp durum Desf.) is an important crop. To identify a source of $\mathrm{Al}^{3+}$ tolerance, we screened diverse Ethiopian durum germplasm. As a center of diversity for durum wheat coupled with the strong selection pressure imposed by extensive acid soils, it was conceivable that $\mathrm{Al}^{3+}$ tolerance had evolved in Ethiopian germplasm. We used a rapid method on seedlings to rate $\mathrm{Al}^{3+}$ tolerance according to the length of seminal roots. From 595 accessions screened using the rapid method, we identified 21 tolerant, 180 intermediate, and 394 sensitive accessions. When assessed in the field the accessions had tolerance rankings consistent with the rapid screen. However, a molecular marker specific for the D-genome showed that all accessions rated as $\mathrm{Al}^{3+}$-tolerant or of intermediate tolerance were hexaploid wheat (Triticum aestivum L.) that had contaminated the durum grain stocks. The absence of $\mathrm{Al}^{3+}$ tolerance in durum has implications for how $\mathrm{Al}^{3+}$ tolerance evolved in bread wheat. There remains a need for a source of $\mathrm{Al}^{3+}$-tolerance genes for durum wheat and previous work that introgressed genes from bread wheat into durum wheat is discussed as a potential source for enhancing the $\mathrm{Al}^{3+}$ tolerance of durum germplasm.

Keywords: aluminum; resistance; Ethiopia; durum; hydroponics; soil acidity; Triticum turgidum ssp. durum Desf.

\section{Introduction}

Durum (Triticum turgidum ssp durum Desf.) wheat and bread wheat (Triticum aestivum L.) provide the Ethiopian population with a large proportion of its caloric intake [1,2]. Despite a general increase in production and productivity of wheat during the last two decades (1998-2016), Ethiopia imports a substantial amount of both durum and bread wheat. Durum production as a proportion of the total wheat produced in Ethiopia has declined over the past few decades from about $80 \%$ in the 1980 s to an estimated current proportion of only about $20 \%$. Despite a reduction in the proportion of grain produced in Ethiopia, durum constitutes $50 \%$ to $80 \%$ of the wheat grain imported in any given year [1], indicating that demand for durum remains strong. One of the abiotic stresses that may be contributing to the decline in durum production is the prevalence of acid soils in Ethiopia. Durum wheat is very sensitive of the toxic $\mathrm{Al}^{3+}$ found in acid soil and is the most sensitive of the small-grained crops to $\mathrm{Al}^{3+}$ 
toxicity [3]. By contrast, bread wheat has $\mathrm{Al}^{3+}$-tolerant alleles of TaALMT1 [4] and TaMATE1B [5] along with other yet to be cloned $\mathrm{Al}^{3+}$-tolerance genes [6].

Worldwide, acidic soils are one of the most important limitations to agricultural production [7]. In Ethiopia, acid soils account for about $34 \%$ of agricultural land area that range from slight to strongly acidic soils [8]. Acid soils generally occupy the western part of the country extending from southwest to northwest, although strongly acidic soils occur mainly in the western part of the country including the lowlands. Acid soils are particularly prevalent in the highlands of Ethiopia [9] and the application of lime commonly results in improved yields of various crops $[10,11]$. The productivity of wheat over acidic areas of Ethiopia is low as compared to parts of the country where soil acidity is absent. For instance, in areas with strongly acidic soils, which occur widely in the western and southwestern parts of the country, the productivity of wheat is as low as 0.8-2.0 $t / h a$. These areas include West Wallaga, Illu-Ababora, Jimma, Gamo Gofa, Asosa, and Metekel zones. On the other hand, a relatively higher grain yield, ranging from 2.5 to $3.1 \mathrm{t} / \mathrm{ha}$, is obtained in regions with near neutral soil $\mathrm{pH}$ including West Arsi, Arsi, Siltie, East Shewa, and Bale zones (Supplementary Materials file, Table S1).

Aluminum is solubilized in acid soils into the toxic $\mathrm{Al}^{3+}$ which in sensitive plants typically affects the viability of the root apex. $\mathrm{Al}^{3+}$ inhibits root growth resulting in reduced uptake of water and nutrients ultimately hindering plant growth and development [12]. In addition to its toxic effects on plant tissues, $\mathrm{Al}^{3+}$ affects nutrient availability within the soil. All of these effects significantly reduce crop yield. While management, primarily by application of lime, is important for neutralizing acid soils, this can be costly and it can take years to correct acidity at depth. A complementary strategy for improving crop production on acid soils is the use of $\mathrm{Al}^{3+}$-tolerant germplasm developed through breeding or genetic modification along with liming practices. In several crop species, variation in $\mathrm{Al}^{3+}$ tolerance has been identified and selective breeding programs can be implemented to increase production on acid soils [13-15]. However as noted above, durum wheat is one of the most $\mathrm{Al}^{3+}$ sensitive of the small-grained crops and shows little variation in $\mathrm{Al}^{3+}$ tolerance [16]. Bread wheat is hexaploid and possesses the A-, B-, and D-genomes whereas durum wheat is tetraploid possessing only the A- and B-genomes. Although, as noted below, a major gene for $\mathrm{Al}^{3+}$ tolerance is found on the D-genome of bread wheat, there are other genes for $\mathrm{Al}^{3+}$ tolerance in bread wheat found on the A- and B-genomes [6]. Early reports that identified $\mathrm{Al}^{3+}$-tolerant durum genotypes with a level of tolerance similar to that of bread wheat [17] can now be attributed to misidentification or contamination of durum grain stocks with bread wheat [18], highlighting the importance of verifying the genetic identity of germplasm. Bread wheat, in contrast to durum, shows a large variation in $\mathrm{Al}^{3+}$ tolerance and much of this is conditioned by alleles of the TaALMT1 gene located on chromosome 4D [19] and TaMATE1B located on chromosome 4B. TaALMT1 encodes an $\mathrm{Al}^{3+}$-activated membrane channel permeable to malate with the malate exuded by root apices binding toxic $\mathrm{Al}^{3+}$ to protect the developing roots. Another $\mathrm{Al}^{3+}$ tolerance gene in bread wheat is TaMATE1B that encodes a citrate transporter in the plasma membrane and in some bread wheat genotypes confers a lower level of tolerance than TaALMT1 [20] whereas in other genotypes TaMATE1B appears to be the predominant $\mathrm{Al}^{3+}$ tolerance gene [21]. Both TaALMT1 and TaMATE1B have been introgressed from bread wheat into durum wheat. This required use of the pairing homeologous (ph1c) mutant to enable TaALMT1 to be transferred from chromosome $4 \mathrm{D}$ in bread wheat to chromosome $4 \mathrm{~B}$ in durum wheat [20]. In contrast to bread wheat, for durum seedlings grown on acid soil, TaMATE1B appears to provide a greater level of $\mathrm{Al}^{3+}$ tolerance than TaALMT1 for reasons that are not understood.

Ethiopia has been considered as a center of diversity for durum germplasm and landraces grown by farmers are a potential source of agronomically important genes [22,23]. A $90 \mathrm{~K}$ single nucleotide polymorphism (SNP) chip analysis supports the notion that durum wheat in Ethiopia is particularly diverse [24]. Furthermore, others undertaking similar phylogenetic analyses based on SNP markers have suggested that Ethiopia is a second center of origin for durum wheat [25]. We speculated that because of the diversity of the durum germplasm coupled with a strong selection pressure imposed by extensive areas of acid soils in Ethiopia useful levels of $\mathrm{Al}^{3+}$ tolerance could have evolved in Ethiopian 
durum landraces. Cultivated durum genotypes sourced from various countries were found to be all $\mathrm{Al}^{3+}$ sensitive [16] whereas others [26] identified relatively tolerant lines in a similar population. The Ethiopian landraces are likely to be more diverse in their genetic makeup than the populations previously screened for tolerance and provide an opportunity to identify unique genes that confer tolerance of acid soils and $\mathrm{Al}^{3+}$ toxicity in particular. As an initial strategy it would be preferable to identify $\mathrm{Al}^{3+}$ tolerance in germplasm already adapted to Ethiopian conditions instead of introgressing genes from other sources. In this study we screened a diverse set of Ethiopian durum germplasm for $\mathrm{Al}^{3+}$ tolerance using a rapid hydroponic screen and then assessed selected lines more thoroughly in the hydroponic screen and finally in field trials on acid soil. Despite Ethiopia having conditions that would favor the evolution of $\mathrm{Al}^{3+}$ tolerance, the diverse durum germplasm was found to be $\mathrm{Al}^{3+}$ sensitive and highlighted the importance of verifying the identity of grain stocks. The absence of $\mathrm{Al}^{3+}$ tolerance genes in diverse durum germplasm suggests that genes encoding $\mathrm{Al}^{3+}$ tolerance found on the A- and B-genomes of bread wheat arose subsequent to the hybridization with the D-genome that produced hexaploid wheat.

\section{Materials and Methods}

\subsection{Germplasm}

A total of 595 durum wheat accessions obtained from the Ethiopian Biodiversity Institute (EBI: www.ibc.gov.et; Supplementary Materials file, Table S2), were screened in a series of non-replicated trials for their $\mathrm{Al}^{3+}$ tolerance using a rapid hydroponic screen. Based on their performance at this preliminary stage, accessions were classified as $\mathrm{Al}^{3+}$-tolerant, -intermediate, or -sensitive (see below). Subsequently all the tolerant as well as selected accessions of the intermediate and sensitive classes, totaling 150 accessions, were evaluated in a replicated hydroponic experiment and a field trial. For the experiments that screened previously identified $\mathrm{Al}^{3+}$-tolerant lines of durum the selected lines are described by Raman et al. [26]. A durum line (Langdon 4D (4B)) that has the 4B chromosome substituted by the $4 \mathrm{D}$ chromosome of bread wheat [27] was included as a positive control of a confirmed $\mathrm{Al}^{3+}$-tolerant durum line [18].

\subsection{Hydroponic Culture}

A rapid hydroponic screening was undertaken using an apparatus comprised of a plastic basin (for holding nutrient solution), a plate that held seed of different wheat accessions separately submerged in nutrient solution and an aeration system (Supplementary Materials file, Figure S1). The method is based on one described previously [16]. Seedlings grown submerged in the aerated nutrient solution remained viable and could be transplanted to soil when required to bulk up grain. Grain harvested from single plants of selected seedlings from this "preliminary" screen was then used in a replicated hydroponic experiment using the same growth conditions. For the replicated experiment, the average performance of 10 seedlings for each accession was determined and the experiment repeated three times.

The nutrient solution comprised of $500 \mu \mathrm{M} \mathrm{KNO}_{3}, 500 \mu \mathrm{M} \mathrm{CaCl}_{2}, 500 \mu \mathrm{M} \mathrm{NH}_{4} \mathrm{NO}_{3}, 150 \mu \mathrm{M}$ $\mathrm{MgSO}_{4}, 10 \mu \mathrm{M} \mathrm{KH}_{2} \mathrm{PO}_{4}, 2 \mu \mathrm{M} \mathrm{FeCl}_{3}$, and $5 \mu \mathrm{M}$ of $\mathrm{Al}_{2} \mathrm{SO}_{4} \cdot 18 \mathrm{H}_{2} \mathrm{O}$ as described previously [28]. The $\mathrm{pH}$ of the solution was adjusted to about 4.3 with $1 \mathrm{M} \mathrm{HCl}$. Dry grain was immersed in the solution and seedlings allowed to grow submerged for 5 days in the solution culture with the nutrient solution changed every day to maintain $\mathrm{pH}$ and $\mathrm{Al}^{3+}$ concentration relatively constant. After 5 days seedlings had typically developed three seminal roots and the total root length was recorded to the nearest $0.1 \mathrm{~cm}$.

We used conventional hydroponics with the same nutrient solution composition as described above to compare the $\mathrm{Al}^{3+}$ tolerance of a set of durum and bread wheat genotypes in a range of $\mathrm{AlCl}_{3}$ concentrations. Relative root length for the various genotypes was calculated after 3 days growth as root length in solution that contained $\mathrm{Al}^{3+}$ relative to root length in control solution that lacked $\mathrm{Al}^{3+}$. Errors associated with relative root length were calculated as described previously [29]. 


\subsection{Determining the Identity of the $A l^{3+}$-Tolerant Accessions}

The morphological similarity between durum and bread wheat made it difficult to establish whether the identified $\mathrm{Al}^{3+}$-tolerant lines were durum or bread wheat by using phenotypic traits alone. Therefore, a polymerase chain reaction (PCR) assay that targeted the Dgas44 sequence was used to determine whether the lines were durum or bread wheat [30]. Dgas44 is a D-genome specific repetitive sequence that can be used to distinguish hexaploid wheat from tetraploid wheats that lack the D-genome [31]. The sequence of forward and reverse primers of Dgas44 marker, respectively, were 5'-CTTCTGACGGGTCAGGGGCAC-3' and 5'-CTGAATGCCCCTGCGGCTTAAG-3'

Ten grain of bulked up samples used in the field trial along with one verified bread wheat cultivar (Enkoy) and one durum wheat accession (8317), distinguished by its reddish/pinkish seed color, were planted in pots. Enkoy variety was included as a positive control (i.e., possesses the D-genome since it is a bread wheat cultivar), while accession 8317 was used as a negative control since it is a known durum accession that lacks the D-genome. Young green leaves were collected separately from three individual plants for DNA extraction. Leaf samples were freeze-dried in liquid nitrogen and pulverized with a Geno/Grinder 2000 and genomic DNA was extracted with a ZymoResearch kit (Plant/Seed MiniPrep) following the manufacturer's protocol. The extracted genomic DNA was quantified with a NanoDrop 2000 UV-Vis Spectrophotometer (Thermo Scientific, Waltham, MA, USA) and PCR of samples undertaken as previously described [18].

\subsection{Field Experiment}

The field experiment was conducted at Bedi $\left(38^{\circ} 36^{\prime} 3^{\prime \prime} \mathrm{E}, 9^{\circ} 5^{\prime} 59^{\prime \prime} \mathrm{N}\right)$, which is located in Watabicha Minjaro Kebele, Welmera District, West Shewa Zone, Oromia Regional State, Ethiopia (Supplementary Materials file, Figure S2). It is situated at approximately $35 \mathrm{~km}$ west of Addis Ababa and about $25 \mathrm{~km}$ away from Holeta town in the north-east. Crops are generally planted from around mid-June, though it varies with crop type and the time of onset of rains.

Samples of the reddish-brown soil to a depth of $20 \mathrm{~cm}$ were collected from the experimental plot with an auger in a regular pattern following a line transect. The soil samples were submitted the following day to JIJE LABOGLASS PLC (Addis Ababa, Ethiopia) for analysis of the major parameters using standard procedures as shown in Table 1. Characterized as a clay type, the $\mathrm{pH}$ of a water extract of the soils was found to be 4.92 indicating acidity and the likely presence of $\mathrm{Al}^{3+}$ toxicity. Note that a water extract will generally have a higher $\mathrm{pH}$ value than if a $\mathrm{CaCl}_{2}$ solution is used for the extraction. For the limed treatments $451 \mathrm{~kg}$ of $\mathrm{CaCO}_{3}$ was manually applied to the soil the year prior to the trial covering an area of $200 \mathrm{~m}^{2}$. The lime was obtained from Guder Lime Factory (Guder, West Shewa Zone, Ethiopia) through collaboration with Oromia Agriculture and Rural Development Bureau. The plot was then ploughed immediately and re-ploughed after a week to thoroughly mix the lime with the soil to a depth of about $20 \mathrm{~cm}$ so that $\mathrm{Al}^{3+}$ would be detoxified in the soil solution.

A total of 150 accessions were selected based on their response to $\mathrm{Al}^{3+}$ toxicity in the preliminary hydroponic screen described above. These accessions were planted during the major rainy season on limed and un-limed plots in the field using a randomized complete block design. The two treatments of the experiment (limed and un-limed blocks) were each replicated twice, and the replicated blocks were spaced $1 \mathrm{~m}$ apart such that the long edge of the blocks were arranged adjacent to one another. All 150 accessions were planted side by side in each block resulting in a total area of $30 \times 2 \mathrm{~m}$ for each block. Individual accessions were planted within the blocks randomly in single rows $2 \mathrm{~m}$ long with $20 \mathrm{~cm}$ spacing between rows. Contamination of un-limed plots with lime through erosion and splashing was avoided by considering slope and spacing factors in the experimental layout. Specifically, plots at a higher slope were assigned as un-limed plots and were separated from the limed plots by $2 \mathrm{~m}$. $\mathrm{N}$ and $\mathrm{P}$ fertilizers were applied after 3-4 weeks of planting as urea and di-ammonium phosphate at blanket recommendation rate $(100 \mathrm{~kg} / \mathrm{ha})$ since there was no pre-determined site-specific fertilizer application rate. Hand-weeding was done at early seedling stage (about one month) and before the booting stage. Mature plants were harvested to measure total biomass and grain yield. 
Table 1. Chemical and physical characteristics of the soils of the study area.

\begin{tabular}{|c|c|c|}
\hline \multicolumn{2}{|c|}{ Soil Parameter } & Value \\
\hline \multicolumn{2}{|c|}{ pH (water extract; 1:1.25) } & 4.92 \\
\hline \multicolumn{2}{|c|}{ Buffer pH (water extract 1:2) } & 5.57 \\
\hline \multicolumn{2}{|c|}{ Electrical conductivity (dS/m) } & 0.07 \\
\hline \multicolumn{2}{|c|}{ Organic matter (\%) } & 4.01 \\
\hline \multicolumn{2}{|c|}{ Total N (\%) } & 0.78 \\
\hline \multicolumn{2}{|c|}{ Available P (mg/kg) } & 8.87 \\
\hline \multicolumn{2}{|c|}{ Exchangeable acidity (meq/100 g) } & 2.23 \\
\hline \multirow{4}{*}{$\begin{array}{l}\text { CEC and exchangeable } \\
\text { bases }(\mathrm{cmol}(+) / \mathrm{kg})\end{array}$} & CEC & 27.19 \\
\hline & $\mathrm{Ca}$ & 5.27 \\
\hline & $\mathrm{Mg}$ & 0.66 \\
\hline & K & 0.91 \\
\hline \multirow{4}{*}{ Texture } & Clay $(\%)$ & 59 \\
\hline & Silt $(\%)$ & 28 \\
\hline & Sand $(\%)$ & 13 \\
\hline & Soil class & Clay \\
\hline
\end{tabular}

\subsection{Statistical Analysis}

Normality of distributions of the replicated hydroponic and field data were tested with SPSS version 24 (IBM SPSS statistics for Windows 2016, Version 24.0. Armonk, NY, USA: IBM Corp.) and RStudio (version 1.0.143: Integrated Development for R. RStudio, Inc., Boston, MA, USA. Retrieved from www.rstudio.com). The non-parametric (Kruskal-Wallis) and parametric ANOVA were computed either with RStudio or SPSS in order to determine whether there was significant difference between accessions for their performance in $\mathrm{Al}^{3+}$ treatments. The general linear model in which both accessions and replications were considered as fixed factors was used for analysis of variance. The median absolute deviation, a non-parametric statistic, was computed with RStudio to assess the level of variability attributed to the trait. Furthermore, post-hoc analysis was conducted using Tukey's honestly significant difference for parametric statistics, while a nonparametric post-hoc was done with Dunn's test, a Kruskal-Wallis test based post-hoc with "agricolae" package of RStudio. The coefficient of determination $\left(\mathrm{r}^{2}\right)$ was calculated to examine the relationship between various variables.

\section{Results}

\subsection{Hydroponic Screen}

Durum wheat accessions (595) were initially screened for $\mathrm{Al}^{3+}$ tolerance using a rapid hydroponic method of submerged seedlings. These accessions sometimes comprised of two or more genotypes since there was a large variation in performance between individual plants of the accession (Figure 1). Furthermore, there were visually observable differences within an accession such as variation in grain color. To take this heterogeneity into account an accession was scored based on its best-performing seedling. The use of average performance of plants in representing an accession would have resulted in rejection of many accessions because of a poor average performance such that a single plant within the accession with an acceptable level of $\mathrm{Al}^{3+}$ tolerance would be lost.

Accessions were classified into three phenotypic classes based on their total root length as tolerant $(\geq 3.1 \mathrm{~cm})$, intermediate $(\leq 3.0 \mathrm{~cm}$ but $\geq 2.1 \mathrm{~cm})$ and susceptible $(\leq 2.0 \mathrm{~cm})$. Moreover, accession 6956 was included in the tolerant class because of its exceptionally long primary seminal root. Using this 
criterion 21 accessions were classed as tolerant, 180 as intermediate, and 394 as susceptible to $\mathrm{Al}^{3+}$ toxicity (Supplementary Materials file, Table S3).

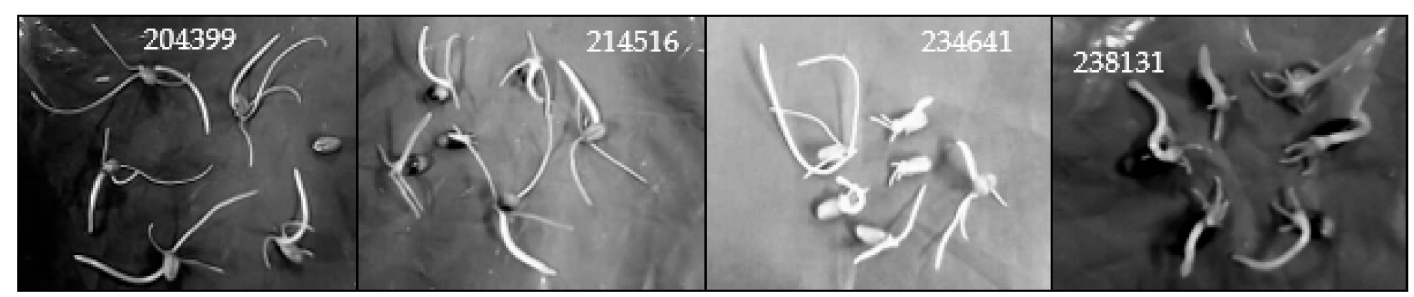

Figure 1. Examples of seedlings grown for 5 days in $\mathrm{Al}^{3+}$-containing nutrient solution. Accessions 204399 and 214516 were scored as tolerant as was accession 234641 that was clearly segregating for tolerance. Accession 238131 was scored as sensitive. Individual seedlings identified within an accession to be tolerant were planted out to bulk up grain and the harvested grain used in a further hydroponic screen and a field trial.

A total of 150 accessions that included all 21 of the $\mathrm{Al}^{3+}$-tolerant class, 79 of the best performers of the intermediate class, and a random selection of 50 of the sensitive class were evaluated in three replications to more precisely characterize their $\mathrm{Al}^{3+}$ tolerance. In this experiment accessions were represented in each experiment by the average performance of $\geq 10$ seedlings using grain harvested from individually selected seedlings. The performance of accessions in the replicated experiment using the same hydroponic method as the preliminary screen was well correlated with the preliminary screen $\left(r^{2}=0.72\right.$; Figure 2).

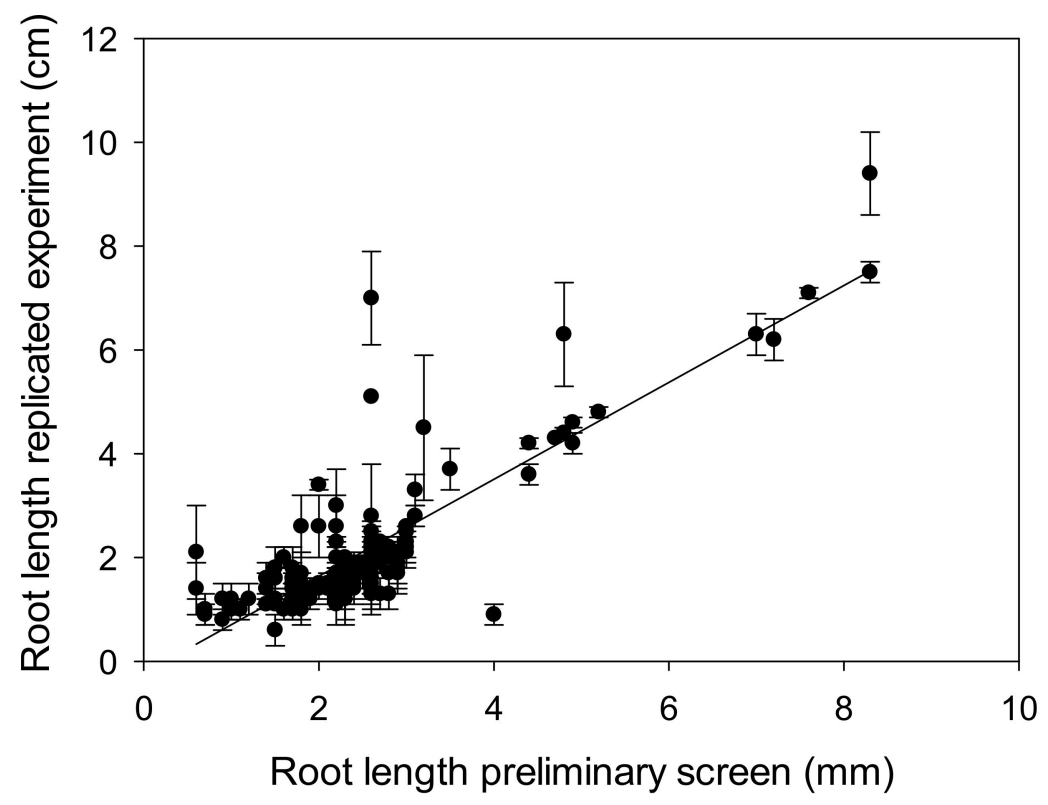

Figure 2. Relationship between total root length of the individual seedlings selected (total root length from the preliminary screen, $n=1$ for each accession) that had the longest roots and the total root length of the resulting progeny of the selections showing the average of 10 or more seedlings (in three replications). Error bars indicate the standard error of the mean for the three replications.

\subsection{Field Experiment}

The set of 150 selections used in the replicated hydroponic screen was assessed in the field on an acid soil. As there was limited grain harvested from single plants of the selected seedlings, the accessions were assessed as single rows $2 \mathrm{~m}$ long on both an un-amended plot and an equivalent plot that had been amended with lime to neutralize the acidity. The grain yield and biomass means for the limed plots of all accessions combined was greater than the means of the acid plot indicating that 
soil acidity was clearly present at this site. Grain yield on the acid site was reduced on average to only $18 \%$ of the limed site whereas biomass was reduced to $28 \%$ of the limed site (Figure 3).

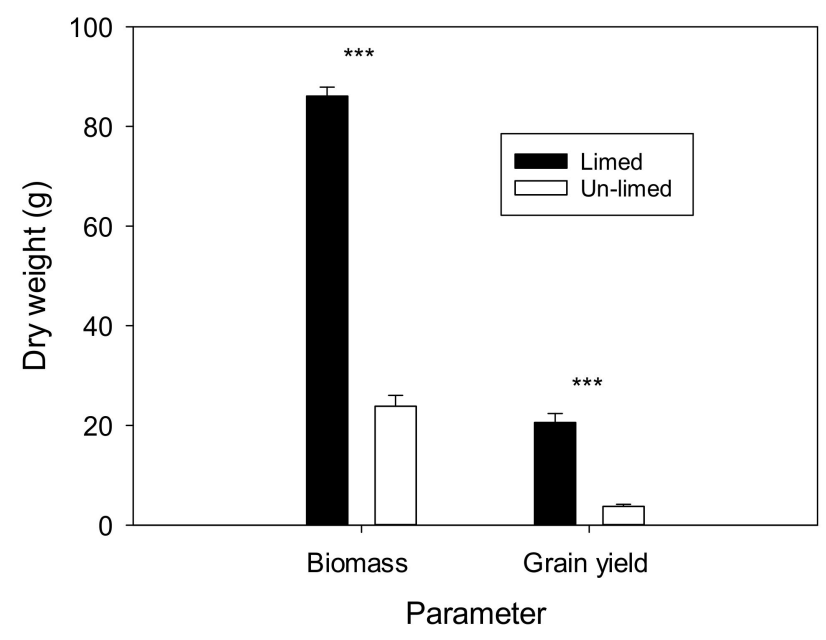

Figure 3. Liming improves biomass and grain yield of Ethiopian accessions grown on an acid soil. Ethiopian accessions (150) were grown in single rows $2 \mathrm{~m}$ long on an acid soil and the same soil that had lime incorporated to a depth of $20 \mathrm{~cm}$. Final biomass and grain yield were determined and data of all accessions were combined with error bars indicating the standard error of the mean $(n=150)$. Student's $t$-test indicated significant differences between treatments $\left({ }^{* * *} ; p<0.001\right)$.

The performance of the $\mathrm{Al}^{3+}$-tolerant lines on the un-limed acid plot was remarkable and clearly distinct from that of the sensitive accessions. Figure 4 shows the relative (un-limed/limed) biomass and grain yields of the accessions selected for the field trial against the root length as determined in the preliminary screen.

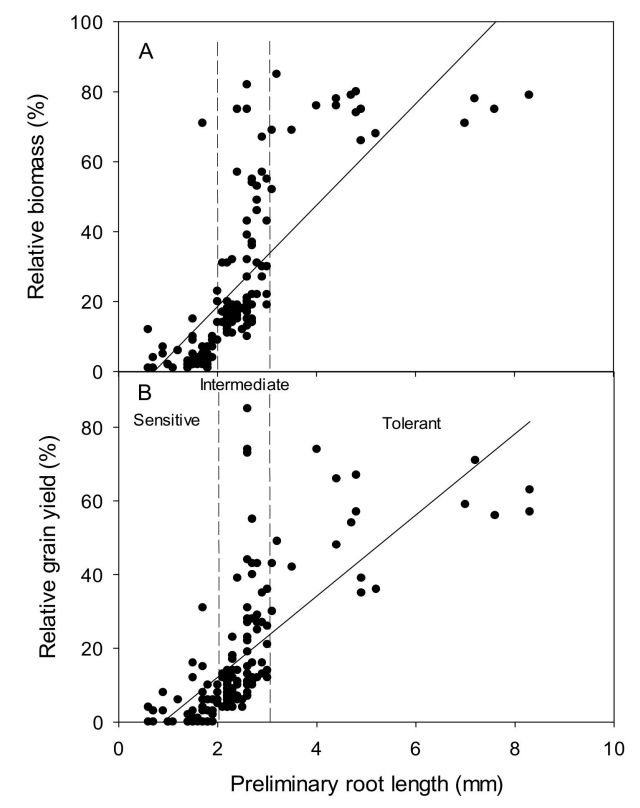

Figure 4. Root length as determined with the rapid screen identifies $\mathrm{Al}^{3+}$-tolerant accessions based on both mature biomass (A) and grain yield (B). The preliminary root length is a measure of the total root length of the most tolerant seedling in the pool of seedlings assessed for each accession. The dashed 
vertical lines denote the cut-off points for root lengths of seedlings initially classed as; tolerant: $>3.0 \mathrm{~cm}$; intermediate: $2.0-3.0 \mathrm{~cm}$; sensitive: $<2.0 \mathrm{~cm}$. The single seedling was grown to seed and the resulting progeny grown in two replicates as $2 \mathrm{~m}$ rows on un-limed and limed plots. The mean of the replicates was used to calculate the relative biomass and relative grain yields where values for the un-limed plots were divided by the limed plots and multiplied by 100 to express data as a percentage. The solid line shows a linear regression with $r^{2}=0.56$ for (A) and $r^{2}=0.52$ for (B).

Expressing data in relative terms takes into account inherent differences in plant vigor when $\mathrm{Al}^{3+}$ is absent but a similar relationship was found when using unmodified data of only the acid plot (Supplementary Materials file, Figure S3). Biomass and final grain yield of genotypes grown in the acid trial were strongly correlated (Figure 5A). When biomass and grain yield data were combined within each grouping of lines selected from the preliminary screen (sensitive, intermediate, and tolerant), they showed rankings consistent with their grouping based on the screen (Figure 5B).
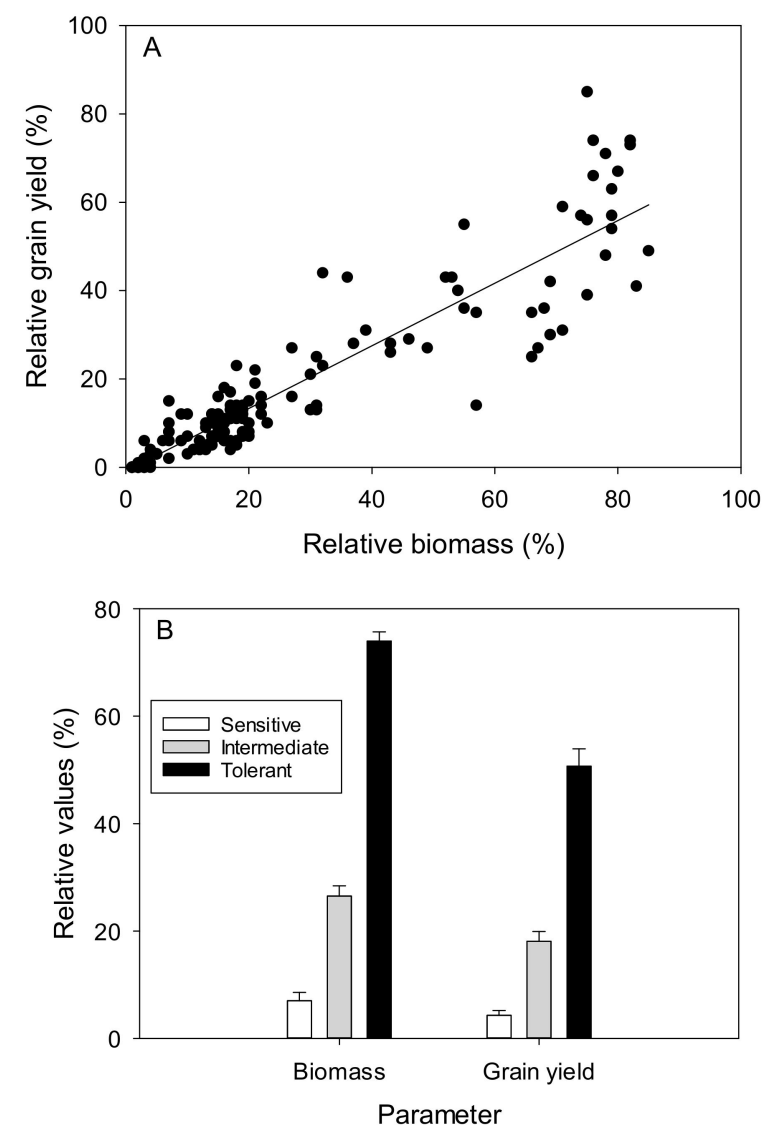

Figure 5. Relative biomass and relative grain yield are highly correlated and the classification of accessions into groups with the preliminary screen of $\mathrm{Al}^{3+}$-tolerant, -intermediate, and -sensitive is consistent with final biomass and grain yield. Biomass and grain yield of accessions grown on the un-limed plot are expressed as a percent of the limed plot using the procedure described in the legend of Figure 4. (A) Relationship between relative biomass and relative grain yield for all accessions grown in the field $\left(r^{2}=0.84\right)$. (B) Relative biomass and relative grain yield of all accessions allocated to the three classes were combined with error bars denoting the standard error and a one-way ANOVA of the data showed significant differences between all groups for each of biomass and grain yield (ANOVA on ranks $p<0.001$ between classes; $n=47$ for Sensitive, $n=83$ for Intermediate, and $n=20$ for Tolerant classes).

Since previous studies have found that stocks of durum wheat lines can be contaminated with bread wheat, we sought to verify that both $\mathrm{Al}^{3+}$-tolerant and -intermediate selections were indeed durum wheat. It can sometimes be difficult to distinguish the species based solely on the phenotypes 
so we used the Dgas molecular marker that is unique to the D-genome to distinguish the species. Using Dgas we found that all the $\mathrm{Al}^{3+}$-tolerant and -intermediate accessions were actually bread wheat (Figure 6), with only the most sensitive genotypes being durum wheat.

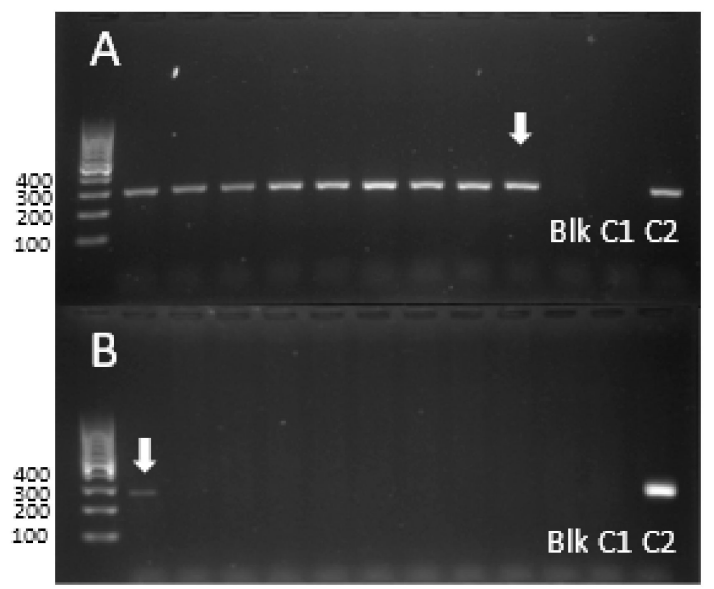

Figure 6. Examples of accessions screened by PCR for the Dgas sequence. Panel (A) is of $\mathrm{Al}^{3+}$-tolerant selections while panel (B) are all $\mathrm{Al}^{3+}$-sensitive selections except for the first lane after the DNA ladder. Most samples are shown as duplicates in lanes side by side except for the last lane of (A) (arrow) whose duplicate is the first lane of (B) (arrow). The lane on the left is a $100 \mathrm{bp}$ DNA ladder with sizes of the smallest four markers shown on the right. A band at about $300 \mathrm{bp}$ is indicative of the presence of the D-genome. Blk is a no DNA sample while C1 is a known durum wheat (accession 8317) and C2 is a known bread wheat variety (Enkoy). All lines (38 lines) that yielded more than $3.5 \mathrm{~g}$ per row in the field trial (Supplementary Materials file, Figure S3B) were analyzed and all possessed the $300 \mathrm{bp}$ band indicating that they were hexaploid wheat.

\subsection{Other Potential Sources of $A l^{3+}$-Tolerant Durum Wheat}

As discussed in the Introduction, the $\mathrm{Al}^{3+}$ tolerance of durum has been enhanced by introgression of genes from bread wheat although not into Ethiopian germplasm [20]. As an alternate source of genes, a previous report identified three out of 420 tetraploid genotypes screened that were comparatively $\mathrm{Al}^{3+}$ tolerant although they did not approach the tolerance shown by a tolerant bread wheat used as a check line [26]. The lines had been confirmed as tetraploid with a molecular marker specific for the D-genome, so these genotypes were a potential source of genes that could be used in direct crosses to Ethiopian lines. To establish if these three lines had a useful level of $\mathrm{Al}^{3+}$ tolerance, we assessed their performance in hydroponic culture against bread wheat lines that varied in tolerance as well as a $4 \mathrm{D}(4 \mathrm{~B})$ substitution line of durum. However, all three lines were rated as sensitive with the best performer having a similar level of tolerance as $\mathrm{Al}^{3+}$-sensitive bread wheat (Figure 7). By contrast, a durum line where the $4 \mathrm{~B}$ chromosome was substituted by the $4 \mathrm{D}$ chromosome of hexaploid wheat had a level of $\mathrm{Al}^{3+}$ tolerance comparable to the tolerant hexaploids. 


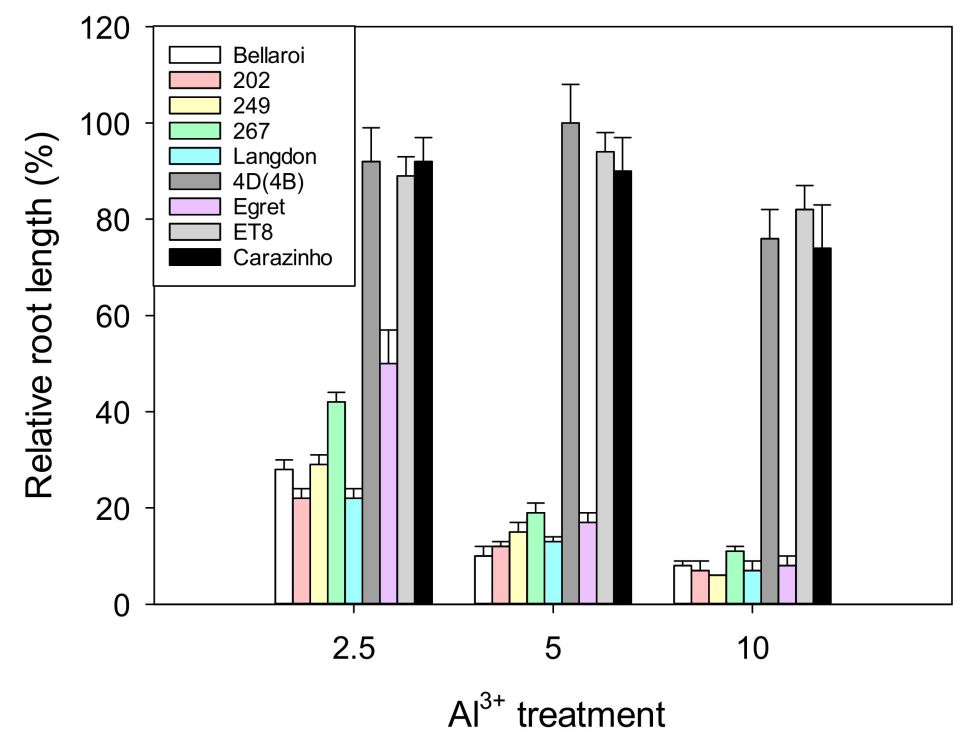

Figure 7. Relative $\mathrm{Al}^{3+}$ tolerance of durum wheat genotypes previously identified as being relatively $\mathrm{Al}^{3+}$ tolerant in comparison to a durum substitution line with chromosome $4 \mathrm{D}$ of bread wheat and bread wheat lines possessing $\mathrm{Al}^{3+}$-tolerant and -sensitive alleles of the TaALMT1 gene. Bellaroi is an Australian durum wheat cultivar; lines 202, 249, and 267 are accessions previously classified as being $\mathrm{Al}^{3+}$-tolerant durum genotypes [26]; Langdon is the parental durum cultivar used to generate the 4D substitution line; $4 \mathrm{D}(4 \mathrm{~B})$ is a durum line in the Langdon background where chromosome $4 \mathrm{~B}$ has been substituted with chromosome 4D; Egret is an $\mathrm{Al}^{3+}$-sensitive bread wheat cultivar; ET8 and Carazinho are $\mathrm{Al}^{3+}$-tolerant bread wheat lines. Root length is expressed as percent relative to a zero control and error bars indicate cumulative errors of three to five seedlings.

\section{Discussion}

\subsection{A Rapid Screen Proves Robust and Correlates with Grain Yield in Field Trials when Ranking Wheat Germplasm for $\mathrm{Al}^{3+}$ Tolerance}

In this work we screened Ethiopian durum accessions for $\mathrm{Al}^{3+}$ tolerance first using a high throughput method with hydroponics, then with a replicated hydroponic screen and finally in the field on acid soil. Ethiopian durum accessions that include landraces are reported to show great diversity for many traits and molecular analyses have verified the unique nature of this germplasm [24]. However, despite this diversity our work shows that there does not appear to be useful levels of $\mathrm{Al}^{3+}$ tolerance in Ethiopian durum wheat and that seedlings identified to be $\mathrm{Al}^{3+}$ tolerant were in fact contaminating bread wheat. It should be noted that many of the accessions classed as tolerant only had a few $\mathrm{Al}^{3+}$-tolerant seedlings indicating that the durum grain stocks had been contaminated with bread wheat grain. This was verified by the use of a molecular marker that confirmed $\mathrm{Al}^{3+}$-tolerant seedlings to be bread wheat. We conclude that the rapid screen was sufficiently robust as a preliminary screen to identify $\mathrm{Al}^{3+}$-tolerant bread wheat contaminants. The accessions ranked as having intermediate tolerance in the preliminary screen could still have conferred a useful level of $\mathrm{Al}^{3+}$ tolerance for durum if they ranked similarly in the field. However, in the field the best performing accessions ranked as having intermediate $\mathrm{Al}^{3+}$ tolerance from the preliminary screen were all identified as bread wheat (Figure 6 and Supplementary Materials Figure S3B). Nevertheless, there exist $\mathrm{Al}^{3+}$-sensitive genotypes of bread wheat so the rapid screen does not replace the use of a molecular marker in identifying bread wheat lines. Verifying the identity of durum wheat grain stocks is of particular importance for germplasm banks but should also be confirmed by researchers. Bread wheat genotypes in the past have been mistakenly identified as durum wheat and the most relevant to this study was the incorrect identification of $\mathrm{Al}^{3+}$-tolerant durum lines that were subsequently found to be bread wheat $[17,18]$. 
In some cases, bread wheat has morphological characteristics in the field that are similar to durum wheat emphasizing the need for molecular analysis to establish the species identity [32].

The absence of $\mathrm{Al}^{3+}$ tolerance in unmodified Triticum turgidum ssp durum Desf. is consistent with previous studies that screened durum cultivars with presumably a lower level of diversity than the Ethiopian germplasm and also showed no or only a comparatively low level of $\mathrm{Al}^{3+}$ tolerance [16]. The simple and rapid screen undertaken with minimal equipment over only 5 days growth with seedlings submerged in nutrient solution showed a remarkable consistency in classifying the relative tolerance of germplasm grown in the field and measured for mature biomass and even grain yield (Figure 5B). Although there was a good general agreement of the hydroponic screens with performance of accessions in the field, there were exceptions. For instance, several accessions rated as having intermediate tolerance with the preliminary screen were the best or amongst the best for grain yield in the field (Figure 4B). This finding emphasizes the importance of verifying selections on acid soil whether in the field or in pots and that while hydroponic screens allow for rapid assessment of germplasm, the relative tolerance of genotypes can differ when grown in soil. For instance, a durum line carrying the TaMATE1B gene introgressed from hexaploid wheat (see below) shows marginal $\mathrm{Al}^{3+}$-tolerance in hydroponics that is considerably less than a line carrying TaALMT1, whereas the situation is reversed when the lines are grown on acid soil, with TaMATE1B lines outperforming TaALMT1 lines [20].

\subsection{The Evolution of $\mathrm{Al}^{3+}$ Tolerance in Bread Wheat Occurred Subsequent to the Hybridization of the D-Genome}

Here we show that durum lines previously reported to be relatively $\mathrm{Al}^{3+}$-tolerant [26] had a level of tolerance similar to sensitive wheat (Figure 7), confirming the absence of useful $\mathrm{Al}^{3+}$ tolerance in durum wheat germplasm (excluding lines where genes from hexaploid wheat have been introgressed as discussed below). This observation is puzzling given reports of the presence of $\mathrm{Al}^{3+}$ tolerance genes on the A- and B-genomes of bread wheat. Although TaALMT1, the major gene for $\mathrm{Al}^{3+}$ tolerance in bread wheat, is located on chromosome $4 \mathrm{D}$, there are several loci on the A- and B-genomes reported to confer $\mathrm{Al}^{3+}$ tolerance [6]. For example, TaMATE1B the only $\mathrm{Al}^{3+}$ tolerance gene other than TaALMT1 that has been cloned from bread wheat, is located on chromosome $4 \mathrm{~B}$ [33]. We surmise that the absence of $\mathrm{Al}^{3+}$ tolerance genes in diverse durum germplasm suggests that the multiple $\mathrm{Al}^{3+}$ tolerance genes found in bread wheat arose subsequent to the hybridization of the D-genome with the A- and B-genomes some 10,000 years ago. Transposable elements have been shown to enhance the level of expression of genes encoding transport proteins such as those of the MATE family [34] that confer $\mathrm{Al}^{3+}$ tolerance. The event of polyploidization commonly results in genome instability including the activation of transposable elements [35]. It is conceivable that activation of transposons when the hexaploid was formed has been key in enabling bread wheat to evolve $\mathrm{Al}^{3+}$ tolerance.

\subsection{Strategies to Enhance the $A l^{3+}$ Tolerance of Ethiopian Durum Wheat}

To date the only durum germplasm verified to be $\mathrm{Al}^{3+}$ tolerant are those that were developed by introgression of $\mathrm{Al}^{3+}$ tolerance genes from bread wheat into durum wheat [20]. In those cases, the ph1c mutant was used to introgress the TaALMT1 gene located on chromosome $4 \mathrm{D}$ of bread wheat and steps taken to avoid the hybrid necrosis that can occur when crossing bread to durum wheat to introgress the TaMATE1B gene on chromosome $4 \mathrm{~B}$. This germplasm is not considered to be genetically modified since it was developed by so-called natural means and can therefore be used in the field without restrictions. The germplasm is a source of $\mathrm{Al}^{3+}$ tolerance genes in a durum background that could be used to introgress one or both genes derived from bread wheat into selected Ethiopian durum germplasm. Many of the farms that grow durum wheat in Ethiopia are small holdings and it has been found that landraces otherwise known as "farmer's varieties" perform better than "improved" germplasm under many situations [36]. With this in mind it may be useful to cross the $\mathrm{Al}^{3+}$-tolerant germplasm described above into selected landraces adapted to local regions. Using local landraces as recurrent parents in multiple backcrosses while tracking the presence of $\mathrm{Al}^{3+}$ tolerance genes using 
molecular markers should maintain the germplasm with various valuable landrace traits that could otherwise be lost [37]. The TaMATE1B gene seems a preferred candidate at this stage since it appears to be more effective than TaALMT1 in a durum background and there exists a co-dominant marker that can be used to track the tolerant allele [20]. A recent publication has shown that the TaMATE1B gene introgressed into a durum genetic background confers a marked ability of roots from mature plants to withstand $\mathrm{Al}^{3+}$ toxicity when grown in an acid soil [38]. A simple backcrossing program where a single gene is introgressed into landraces could be useful in establishing whether or not TaMATE1B can improve durum grain production of landraces on acid soils of Ethiopia. We speculate that introgressing both TaALMT1 with TaMATE1B may provide the greatest level of $\mathrm{Al}^{3+}$ tolerance to durum wheat as has been found for some bread wheat genotypes.

\section{Conclusions}

Here we show that despite the diversity of Ethiopian durum germplasm and large regions of acid soils, conditions conducive for the evolution of $\mathrm{Al}^{3+}$ tolerance, a useful level of $\mathrm{Al}^{3+}$ tolerance was not detected. A high throughput screen identified $\mathrm{Al}^{3+}$-tolerant seedlings within accessions but all of them were shown to be contaminating bread wheat. This finding highlights the importance of correct identification of germplasm and confirmation of species identity with molecular markers particularly for closely-related species. The finding that Ethiopian durum germplasm is $\mathrm{Al}^{3+}$ sensitive is consistent with $\mathrm{Al}^{3+}$ tolerance having evolved in bread wheat subsequent to the hybridization of the D-genome with the A- and B-genomes. A field trial on acid soil showed biomass and grain yields that correlated with classifications based on a high throughput screen, confirming the utility of the rapid screen for preliminary assessment of germplasm.

Supplementary Materials: The following are available online at http://www.mdpi.com/2073-4395/9/8/440/s1, Figure S1: Photographs of the components of the hydroponic system. (A) The plastic cups to which dry grain was added. The holes allowed aeration of grain while the cups themselves separated the accessions from one another. The slots in the plastic stands at the end of a series of cups enabled the long air stone to be inserted and held firm. (B) Top view showing air stones and pumps along with the plastic basin used to hold the nutrient solution. (C) Top view of assembled equipment showing plastic cups with a partitioning plate inserted within each cup so that two accessions could be placed into each cup and separated from one another. Nutrient solution was added to the basin to fill and cover the cups that held the grain. The holes in the cups allowed sufficient aeration for growth of seedlings. Nutrient solution was changed every day to maintain $\mathrm{pH}$ at about 4.3 and $\mathrm{Al}_{2} \mathrm{SO}_{4}$ at $5 \mu \mathrm{M}$. Figure S2: Location of the study area in Ethiopia. Figure S3: Relationships between $\mathrm{Al}^{3+}$ tolerance determined with a rapid screen and (A) biomass or (B) grain yield for durum accessions grown on an acid plot in the field. Table S1: Wheat production across zones and special districts of Ethiopia showing yields averaged over 5 years. Table S2: Passport data of durum accessions used in hydroponics screening for $\mathrm{Al}^{3+}$ tolerance. Table S3: Preliminary screen of $\mathrm{Al}^{3+}$ tolerance of 594 Ethiopian durum wheat accessions grown in $\mathrm{Al}^{3+}$-containing nutrient solution where total root length after 5 days growth was used to classify genotypes.

Author Contributions: Conceptualization, E.F.W.; methodology, E.F.W. and E.D.; formal analysis, E.F.W. and E.D.; investigation, E.F.W., E.D., A.L.O.; resources, E.F.W., A.L.O., K.T., E.M.M.; data curation, E.F.W.; writing—original draft preparation, E.F.W. and E.D.; writing-review and editing, A.L.O., and K.D.; supervision, E.D., A.L.O., K.D., K.T. and S.K.M.; project administration, K.T. and E.M.M.; funding acquisition, E.F.W., A.L.O. and K.T.

Funding: The hydroponic and field experiments were sponsored by Addis Ababa University and the Eastern Africa Agricultural Productivity Program, respectively, while the Dgas analysis was financed by the BecA-ILRI Hub through the Africa Biosciences Challenge Fund (ABCF) program. The ABCF Program is funded by the Australian Department for Foreign Affairs and Trade (DFAT) through the BecA-CSIRO partnership; the Syngenta Foundation for Sustainable Agriculture (SFSA); the Bill \& Melinda Gates Foundation (BMGF); the UK Department for International Development (DFID) and; the Swedish International Development Cooperation Agency (SIDA).

Conflicts of Interest: The authors declare no conflict of interest. The funders had no role in the design of the study; in the collection, analyses, or interpretation of data; in the writing of the manuscript, or in the decision to publish the results. 


\section{References}

1. Minot, N.; Warner, J.; Lemma, S.; Kasa, L.; Gashaw, A.; Rashid, S. The Wheat Supply Chain in Ethiopia: Patterns, Trends, and Policy Options; International Food Policy Research Institute (IFPRI): Washington, DC, USA, 2015.

2. Sall, A.T.; Chiari, T.; Legesse, W.; Seid-Ahmed, K.; Ortiz, R.; van Ginkel, M.; Bassi, M.F. Durum wheat (Triticum durum Desf.): Origin, cultivation and potential expansion in sub-Saharan Africa. Agronomy 2019, 9, 263. [CrossRef]

3. Bona, L.; Wright, R.J.; Baligar, V.C. A rapid method for screening cereals for acid soil tolerance. Cereal Res. Commun. 1991, 19, 465-468.

4. Raman, H.; Ryan, P.R.; Raman, R.; Stodart, B.J.; Zhang, K.; Martin, P.; Wood, R.; Sasaki, T.; Yamamoto, Y.; Mackay, M.; et al. Analysis of TaALMT1 traces the transmission of aluminum resistance in cultivated common wheat (Triticum aestivum L.). Theor. Appl. Genet. 2008, 116, 343-354. [CrossRef] [PubMed]

5. Aguilera, J.G.; Minozzo, J.A.D.; Barichello, D.; Fogaca, C.M.; da Silva, J.P.; Consoli, L.; Pereira, J.F. Alleles of organic acid transporter genes are highly correlated with wheat resistance to acidic soil in field conditions. Theor. Appl. Genet. 2016, 129, 1317-1331. [CrossRef] [PubMed]

6. Raman, H.; Stodart, B.; Ryan, P.R.; Delhaize, E.; Emebiri, L.; Raman, R.; Coombes, N.; Milgate, A. Genome-wide association analyses of common wheat (Triticum aestivum L.) germplasm identifies multiple loci for aluminium resistance. Genome 2010, 53, 957-966. [CrossRef] [PubMed]

7. Von Uexküll, H.R.; Mutert, E. Global extent, development and economic impact of acid soils. Plant Soil 1995, 171, 1-15. [CrossRef]

8. Wayima, E.F. Classification of Ethiopian soils with pH. J. Soil Sci. Environ. Manag. 2019, in press.

9. Kidanemariam, A.; Gebrekidan, H.; Mamo, T.; Kibret, K. Impact of altitude and land use type on some physical and chemical properties of acidic soils in Tsegede highlands, northern Ethiopia. Open J. Soil Sci. 2012, 2, 223-233. [CrossRef]

10. Kidanemariam, A.; Gebrekidan, H.; Mamo, T.; Tesfaye, K. Wheat crop response to liming materials and N and P fertilizers in acidic soils of Tsegede highlands, northern Ethiopia. Agric. For. Fish. 2013, 2, 126-135. [CrossRef]

11. Mosissa, F. Progress of soil acidity management research in Ethiopia. Greener J. Soil Sci. Plant Nutr. 2018, 5, 9-22. [CrossRef]

12. Kochian, L.V.; Pineros, M.A.; Liu, J.P.; Magalhaes, J.V. Plant adaptation to acid soils: The molecular basis for crop aluminum resistance. Ann. Rev. Plant Biol. 2015, 66, 571-598. [CrossRef] [PubMed]

13. Magalhaes, J.V.; Garvin, D.F.; Wang, Y.H.; Sorrells, M.E.; Klein, P.E.; Schaffert, R.E.; Li, L.; Kochian, L.V. Comparative mapping of a major aluminum tolerance gene in sorghum and other species in the Poaceae. Genetics 2004, 167, 1905-1914. [CrossRef] [PubMed]

14. Bian, M.; Waters, I.; Broughton, S.; Zhang, X.Q.; Zhou, M.X.; Lance, R.; Sun, D.F.; Li, C.D. Development of gene-specific markers for acid soil/aluminium tolerance in barley (Hordeum vulgare L.). Mol. Breed. 2013, 32, 155-164. [CrossRef]

15. Ma, J.F.; Nagao, S.; Sato, K.; Ito, H.; Furukawa, J.; Takeda, K. Molecular mapping of a gene responsible for Al-activated secretion of citrate in barley. J. Exp. Bot. 2004, 55, 1335-1341. [CrossRef] [PubMed]

16. Ryan, P.R.; Raman, H.; Gupta, S.; Sasaki, T.; Yamamoto, Y.; Delhaize, E. The multiple origins of aluminium resistance in hexaploid wheat include Aegilops tauschii and more recent cis mutations to TaALMT1. Plant J. 2010, 64, 446-455. [CrossRef] [PubMed]

17. Foy, C.D. Tolerance of durum wheat lines to an acid, aluminum-toxic subsoil. J. Plant Nutr. 1996, 19, $1381-1394$. [CrossRef]

18. Han, C.; Ryan, P.R.; Yan, Z.; Delhaize, E. Introgression of a 4D chromosomal fragment into durum wheat confers aluminium tolerance. Ann. Bot. 2014, 114, 135-144. [CrossRef]

19. Delhaize, E.; Ma, J.F.; Ryan, P.R. Transcriptional regulation of aluminium tolerance genes. Trends Plant Sci. 2012, 17, 341-348. [CrossRef]

20. Han, C.; Zhang, P.; Ryan, P.R.; Rathjen, T.M.; Yan, Z.H.; Delhaize, E. Introgression of genes from bread wheat enhances the aluminium tolerance of durum wheat. Theor. Appl. Genet. 2016, 129, 729-739. [CrossRef]

21. Garcia-Oliveira, A.L.; Martins-Lopes, P.; Tolra, R.; Poschenrieder, C.; Guedes-Pinto, H.; Benito, C. Differential physiological responses of Portuguese bread wheat (Triticum aestivum L.) genotypes under aluminium stress. Diversity 2016, 8, 26. [CrossRef] 
22. Mengistu, D.K.; Kidane, Y.G.; Fadda, C.; Pe, M.E. Genetic diversity in Ethiopian durum wheat (Triticum turgidum var durum) inferred from phenotypic variations. Plant Genet. Res. Charact. Util. 2018, 16, 39-49. [CrossRef]

23. Mengistu, D.K.; Kiros, A.Y.; Pe, M.E. Phenotypic diversity in Ethiopian durum wheat (Triticum turgidum var. durum) landraces. Crop J. 2015, 3, 190-199. [CrossRef]

24. Mengistu, D.K.; Kidane, Y.G.; Catellani, M.; Frascaroli, E.; Fadda, C.; Pe, M.E.; Dell'Acqua, M. High-density molecular characterization and association mapping in Ethiopian durum wheat landraces reveals high diversity and potential for wheat breeding. Plant Biotechnol. J. 2016, 14, 1800-1812. [CrossRef] [PubMed]

25. Kabbaj, H.; Sall, A.T.; Al-Abdallat, A.; Geleta, M.; Amri, A.; Filali-Maltouf, A.; Belkadi, B.; Ortiz, R.; Bassi, F.M. Genetic diversity within a global panel of durum wheat (Triticum durum) landraces and modern germplasm reveals the history of alleles exchange. Front. Plant Sci. 2017, 8, 1277. [CrossRef] [PubMed]

26. Raman, H.; Hare, R.; Graham, K.; Coombes, N.; Raman, R. Characterisation of durum germplasm for aluminium resistance using nutrient solution culture. In International Wheat Genetics Symposium; Appels, R., Lagudah, R.E.E., Langridge, P., Mackay, M., McIntyre, L., Sharp, P., Eds.; Sydney University Press: Brisbane, Australia, 2008; pp. 1-3.

27. Joppa, L.R.; Williams, N.D. Langdon durum disomic substitution lines and aneuploid analysis in tetraploid wheat. Genome 1988, 30, 222-228. [CrossRef]

28. Delhaize, E.; Ryan, P.R.; Hebb, D.M.; Yamamoto, Y.; Sasaki, T.; Matsumoto, H. Engineering high-level aluminum tolerance in barley with the ALMT1 gene. Proc. Natl. Acad. Sci. USA 2004, 101, 15249-15254. [CrossRef] [PubMed]

29. Zhou, G.F.; Delhaize, E.; Zhou, M.X.; Ryan, P.R. The barley MATE gene, HvAACT1, increases citrate efflux and $\mathrm{Al}^{+3}$ tolerance when expressed in wheat and barley. Ann. Bot. 2013, 112, 603-612. [CrossRef] [PubMed]

30. Bryan, G.J.; Dixon, A.; Gale, M.D.; Wiseman, G. A PCR-based method for the detection of hexaploid bread wheat adulteration of durum wheat and pasta. J. Cereal Sci. 1998, 28, 135-145. [CrossRef]

31. McNeil, D.; Lagudah, E.S.; Hohmann, U.; Appels, R. Amplification of DNA-sequences in wheat and its relatives-the Dgas44 and R350 families of repetitive sequences. Genome 1994, 37, 320-327. [CrossRef]

32. Zeven, A.C.; Waninge, J. The presence of 3 groups of Scalavatis and other hexaploid bread wheat plants contaminating durum-wheat fields in Cyprus. Euphytica 1989, 43, 117-124. [CrossRef]

33. Tovkach, A.; Ryan, P.R.; Richardson, A.E.; Lewis, D.C.; Rathjen, T.M.; Ramesh, S.; Tyerman, S.D.; Delhaize, E. Transposon-mediated alteration of TaMATE1B expression in wheat confers constitutive citrate efflux from root apices. Plant Physiol. 2013, 161, 880-892. [CrossRef]

34. Pereira, J.F.; Ryan, P.R. The role of transposable elements in the evolution of aluminium resistance in plants. J. Exp. Bot. 2019, 70, 41-54. [CrossRef] [PubMed]

35. Madlung, A.; Tyagi, A.P.; Watson, B.; Jiang, H.; Kagochi, T.; Doerge, R.W.; Martienssen, R.; Comai, L. Genomic changes in synthetic Arabidopsis polyploids. Plant J. 2005, 41, 221-230. [CrossRef] [PubMed]

36. Kidane, Y.G.; Mancini, C.; Mengistu, D.K.; Frascaroli, E.; Fadda, C.; Pe, M.E.; Dell'Acqua, M. Genome wide association study to identify the genetic base of smallholder farmer preferences of durum wheat traits. Front. Plant Sci. 2017, 8, 1230. [CrossRef] [PubMed]

37. Tsegaye, B.; Berg, T. Genetic erosion of Ethiopian tetraploid wheat landraces in Eastern Shewa, Central Ethiopia. Genet. Resour. Crop Evol. 2007, 54, 715-726. [CrossRef]

38. Pooniya, V.; Palta, J.A.; Chen, Y.; Delhaize, E.; Siddique, K.H. Impact of the TaMATE1B gene on above and below-ground growth of durum wheat grown on an acid and $\mathrm{Al}^{3+}$-toxic soil. Plant Soil 2019, 1-12. [CrossRef]

(C) 2019 by the authors. Licensee MDPI, Basel, Switzerland. This article is an open access article distributed under the terms and conditions of the Creative Commons Attribution (CC BY) license (http://creativecommons.org/licenses/by/4.0/). 